\title{
CONCEITOS E VALORES EM EDUCAÇÃO AMBIENTAL: UMA EXPERIÊNCIA COM ALUNOS QUE NÃO CONSEGUIAM JUNTAR ÁREA VERDE E CIDADE
}

\section{Dalva Maria Bianchini Bonotto*}

* Professora de Ciências e Biologia, mestre em Conservação e Manejo de Recursos pelo Centro de Estudos Ambientais da UNESP, doutoranda do Programa de Pós Graduação em Educação do Centro de Educação e Ciências Humanas da UFSCar. (e-mail: dbonotto@claretianas.com.br)

\section{RESUMO}

Esse artigo, elaborado a partir de uma caso de ensino, apresenta as reflexões de uma professora do ensino médio ao tentar trabalhar com a educação ambiental em sala de aula. É enfatizada a complexidade do trabalho educativo com o conteúdo atitudinal, apontando-se a necessidade do preparo adequado para a efetivação de um ensino que tencione abarcar a dimensão dos valores.

\section{ABSTRACT}

This paper is based on a study concerning the environmental education, and shows the reflexions of a teacher while trying to work with her high school students. The complexity of the educational work with the attitudinal content is emphasized, indicating the need of an appropriated preparation in order to establish a teaching that intends to comprise the values dimension.

PALAVRAS-CHAVE: Caso de ensino; educação ambiental; conteúdo atitudinal; conceitos; valores.

\section{INTRODUÇÃO}

Como instrumento auxiliar do processo de desenvolvimento profissional da 
docência, tem-se considerado importante a utilização de casos de ensino, narrativas detalhadas de experiências de ensino que apresentam como um professor agiu em determinada situação de sala de aula.

A análise desses casos pode auxiliar a construção do conhecimento profissional de professores, pois o exame e reflexão sobre a prática da sala de aula podem possibilitar o estabelecimento de relações entre teoria e prática; o aprofundamento do conteúdo da área específica de conhecimento;(...) o estudo de vários temas, tais como tópicos/conceitos específicos de diversas áreas do conhecimento (MIZUKAMI, 2000, p.156), dentre outros benefícios.

O tema Meio Ambiente foi apontado pelos atuais Parâmetros Curriculares Nacionais como um dos temas transversais, de alto interesse para a sociedade, o que torna a educação ambiental uma tarefa de todos os professores. Ao considerarmos a complexidade do tema, sentimos o quanto seria útil a divulgação das experiências significativas de professores envolvidos nessa tarefa, com o intuito de permitir o aprofundamento das reflexões sobre os caminhos trilhados, facilidades e dificuldades encontradas, contribuindo assim para a efetivação desse processo.

Com essa perspectiva procuraremos trazer algumas reflexões sobre a educação ambiental, a partir de um caso de ensino. Ele apresenta as experiências de uma professora de ensino médio que, preparando-se para o trabalho com um determinado conteúdo conceitual, depara-se com a dimensão valorativa, a qual deve também atender em sua função docente.

\section{O CASO DE ENSINO}

CLASSE: $1^{\circ}$ série do ensino médio

DISCIPLINA: Biologia

UNIDADE: Tópicos básicos de Ecologia em associação ao tema transversal Meio Ambiente

TEMA: A importância das áreas verdes para a cidade: aspectos ecológicos e estéticos

OBJETIVOS: análise das influências das áreas verdes na cidade, compreensão de sua importância para o ambiente urbano.

PROCEDIMENTOS: exposição dialogada a respeito da influência das áreas verdes na cidade; leitura em grupo de um texto-síntese sobre o assunto tratado; 
elaboração de cartazes pelos grupos, veiculando essas informações.

RECURSOS: texto para cada grupo; material para a confecção do cartaz a ser providenciado pelas equipes.

AVALIAÇÃO: envolvimento e participação nas atividades; trabalho final (cartaz).

Tendo definido a unidade geral e o tema a ser trabalhado, a professora escolheu os conceitos que considerava importantes e elaborou as atividades de ensino, partindo para o seu desenvolvimento.

Algum tempo da aula foi gasto com a exposição inicial do assunto e a leitura geral de um texto por ela elaborado, seguindo-se uma proposta de atividade para os alunos. Nessa tarefa, ela solicitou para cada grupo de alunos que escolhesse um dos aspectos apontados no texto em que as áreas verdes contribuem com a manutenção de melhores condições de vida urbana para a população. A partir disso os alunos deveriam elaborar um cartaz que veiculasse essa informação de forma atrativa, divulgando o assunto para outras pessoas, com o objetivo de estimular a valorização dessas áreas. Eles desenvolveriam, assim, uma campanha de esclarecimento.

Com isso a professora buscava, além de propiciar a compreensão dos alunos sobre os aspectos apresentados e avaliar essa aprendizagem (pois as idéias do texto deveriam ser apresentadas em imagens e frases curtas, o que exigiria tal compreensão), exercitar os alunos na tradução das informações objetivas através de outros meios de expressão, utilizando-se de uma linguagem mais informal. A atividade toda implicaria em ir além da simples capacidade de compreensão do assunto, envolvendo também a aplicação dos conhecimentos em uma tarefa diferente. Ela seria mais rica que os exercícios costumeiros de compreensão de texto. A professora estava feliz com a proposta elaborada.

Os vários aspectos em que as áreas verdes beneficiam as cidades, citados no texto, foram então identificados e cada equipe ficou incumbida de trabalhar com um deles.

A partir daí a professora dirigiu-se a cada grupo para acompanhar seus trabalhos. Surgiram então, por parte dos alunos, as incompreensões com relação às informações e conceitos, as dúvidas não apontadas durante a exposição inicial feita pela professora ou na leitura do texto. Prosseguiram as orientações da professora, que buscava auxiliar os alunos com novos esclarecimentos. Este processo já era esperado por ela, imaginando que, à medida que os alunos fossem finalmente compreendendo o assunto, conseguiriam elaborar os cartazes.

Mas, ao lado daquelas dificuldades, que eram esperadas, surgiu outra, 
totalmente imprevista: a professora percebeu a dificuldade dos alunos em associar, em seus cartazes, área verde e cidade! À medida que os esboços dos desenhos foram surgindo, apareceu uma tendência gritante em separar, na figura, a cidade da área verde, $\mathrm{o}$ que causou estranheza à professora, que pôs-se a refletir sobre o fato.

Procurando uma explicação para o ocorrido ela recordou-se de algumas leituras que havia feito e que apontavam um aspecto presente em nossa sociedade atual como predominante: a dicotomia sociedade-natureza, crença que acarreta uma dificuldade em nos considerarmos como parte da natureza, favorecendo, pelo contrário, que nos coloquemos à parte dela. Tal dicotomia seria endossada inclusive pela própria ciência moderna, que se apóia na separação sujeito-objeto:

(...)a razão cartesiana pressupõe a divisibilidade infinita do objeto. A indivisibilidade do espírito é a divisibilidade do objeto (...) É na base desta cisão radical entre sujeito e objeto que se pautará praticamente todo o conhecimento científico subseqüente. O sujeito é o 'cogito' e o mundo, seu objeto. É na base desse dualismo que encontramos a gênese filosófica da crise ecológica moderna, pois a partir desta cisão a natureza não é mais que um objeto passivo à espera do corte analítico. Os seres humanos retiram-se da natureza. Eles vêem a natureza como quem olha uma fotografia. A natureza e a cultura passam a ser duas coisas muito distintas. Aliás, este é agora o novo ideal de educação: distinguir-se o mais possivel da natureza, tornar-se humano. (GRÜN, 1996, p.35)

A tendência encontrada nos trabalhos dos alunos evidenciava esta separação sociedade-natureza, apontada em inúmeros artigos sobre a temática ambiental, muitos dos quais têm advertido para a necessidade de valorizarmos e desenvolvermos uma visão mais integrativa entre ambos. Esta dicotomia estava se revelando ali com clareza, aparecendo espontaneamente por entre os desenhos dos alunos, sem que nenhum deles disso se apercebesse, apesar de já terem discutido sobre o assunto. E será que a professora o perceberia, sem a reflexão teórica mais aprofundada que fazia na ocasião?

Como proceder, enquanto professora, diante do ocorrido? Ela sentia que o fato não poderia ser ignorado nem subestimado, pois apresentava-se espontaneamente uma ocasião para trabalhar novamente com os alunos esse aspecto, fundamental nas discussões a respeito da temática ambiental:

Uma das questões mais complexas levantadas pelo movimento ambientalista é a que diz respeito a questão da relação do homem, organizado em sociedade, com a natureza(...) Não podemos, portanto, reduzir as questões ambientais apenas ao tratamento dos seus aspectos naturais.(CARVALHO, 1989, p.219-220) 
A redução das questões ambientais aos seus aspectos naturais acarreta uma visão restrita e equivocada desses problemas, não se avançando na compreensão de sua complexidade - que se estende para além dos aspectos naturais - e, em conseqüência, nas possibilidades de uma intervenção mais adequada diante deles.

Isso tudo era claro para a professora. Mas ela estava com dificuldades de aliar essas reflexões com o prosseguimento das atividades junto aos alunos: a proposta da associação entre área verde e cidade, como é que ficaria agora? O que fazer?

A professora optou inicialmente por sugerir, sutilmente, que os alunos integrassem mais a cidade e a área verde em seus desenhos...

(A professora frente à classe): Pessoal, quando comecei a observar os seus trabalhos, vi que muitos de vocês estavam começando a escrever aquelas frases costumeiras, "preserve o verde", "o verde é vida" e desenhar uma mata nas margens de um rio... mas, ó, não é isso! A gente está trabalhando com áreas verdes dentro da cidade. Não adianta pôr um rio distante com mata ciliar dos dois lados, não que isso não seja importante. Mas nesse momento a gente quer mostrar, para quem ver o trabalho, a importância da área verde aqui, tá; onde é que ela vai barrar a erosão aqui, onde ela vai trazer umidade e assim por diante!...

Entretanto, mesmo com essa interferência, o resultado final dos trabalhos apresentou fortemente a tendência da separação. A real integração de área verde ao ambiente urbano não foi esquematizada espontaneamente e as orientações da professora já não tão sutis - ocorreram até o dia da apresentação dos cartazes, quando ela continuava sugerindo a um e outro grupo algumas mudanças no desenho do cartaz que permitissem suavizar tal tendência.

Praticamente a metade dos cartazes elaborados apresentou inclusive uma divisão, tendo de um lado uma cidade, sem áreas verdes, e do outro, a área verde, sem cidade ou, quando muito, uma imagem que lembrava as zonas urbana e rural, separadas (figura 1). Um dos cartazes passou até a mensagem de eliminação da cidade de nossas vidas, descaracterizando totalmente o que se pretendia divulgar (figura 2). 


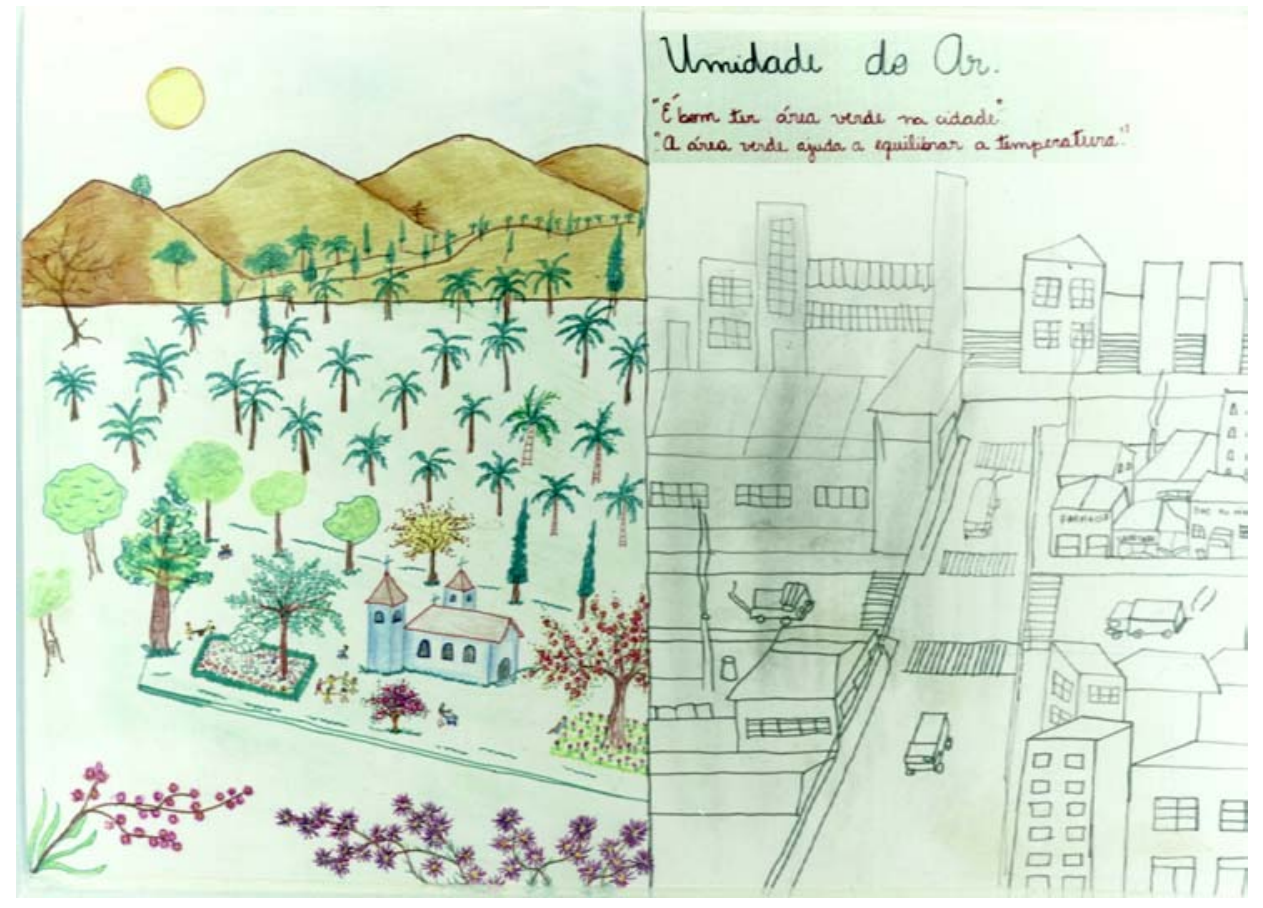

Figura 1 - Cartaz elaborado por uma equipe de alunos do ensino médio, a respeito da importância das áreas verdes para a cidade, em que se observa de um lado a representação de uma zona rural com área verde e do outro, a zona urbana sem área verde.

Alguns cartazes conseguiram veicular a mensagem desejada de maneira menos problemática, pois em seus desenhos ou não envolveram diretamente a cidade ou presentaram o problema sem proporem uma solução.

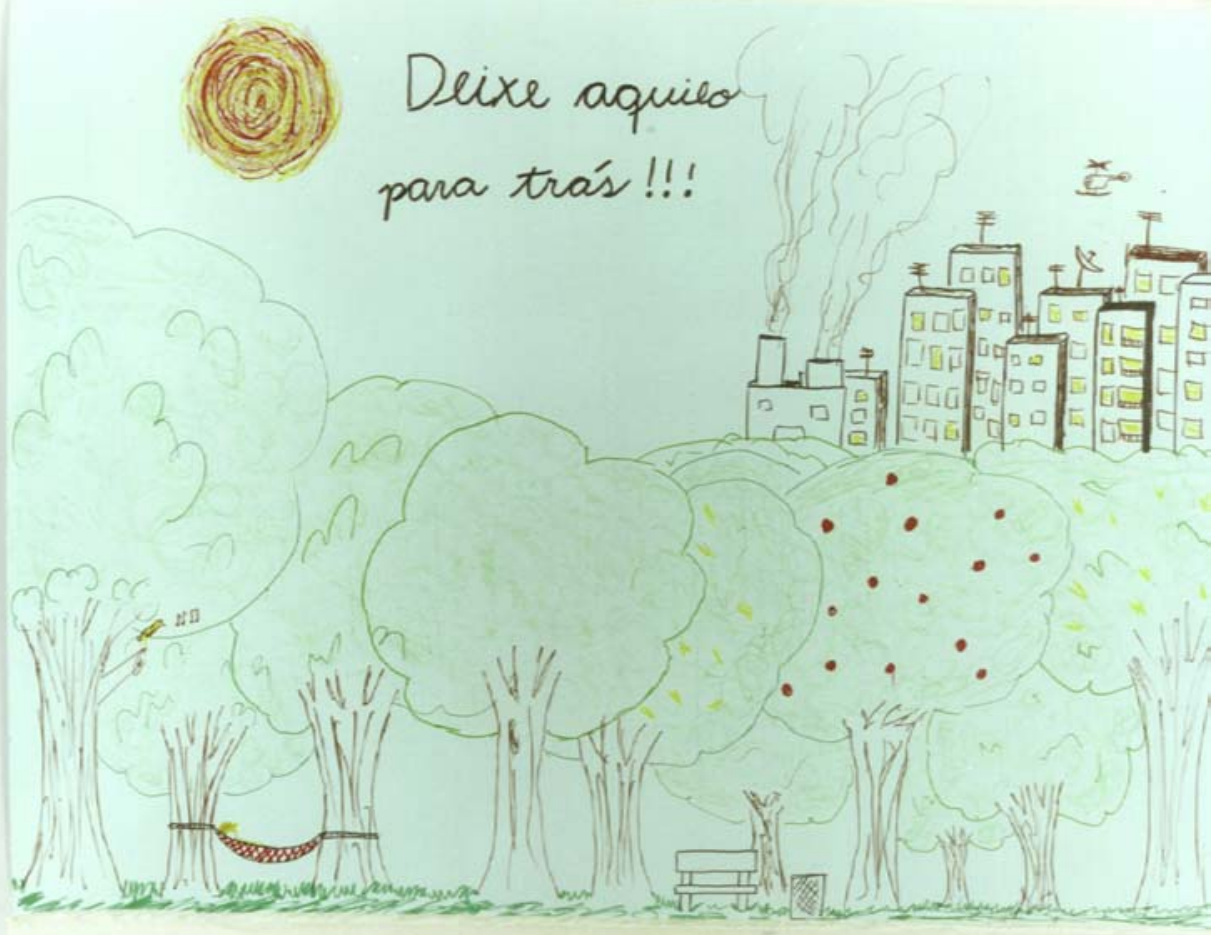


Figura 2 - Cartaz elaborado por uma equipe de alunos do ensino médio, a respeito da importância das áreas verdes para a cidade, em que se observa a descaracterização da mensagem que se pretendia divulgar.

A atividade com o desenho possibilitou assim a clarificação de um valor que não aparecia na fala dos alunos durante o trabalho, mas que estava presente no íntimo deles mesmos, integrantes que são dessa sociedade cujas crenças e valores procuramos rever nesse processo de nos educarmos para o ambiente. A visão da sociedade separada da natureza parecia emergir dessa experiência como aspecto fundamental, como um valor. Este influenciava a elaboração de desenhos dos alunos, que não conseguiam imaginar espontaneamente a integração entre o ambiente urbano e áreas verdes. A atividade com o desenho mostrou-se assim ser um instrumento valioso para o trabalho educativo com valores, facilitando a sua manifestação, ou seja, permitindo sua clarificação:

Os múltiplos exercícios que costumam incluir-se sob a perspectiva metodológica da clarificação de valores, têm como principal objetivo facilitar a tomada de consciência dos valores, crenças e opções vitais de cada pessoa. Pretende-se, portanto, ou iluminar melhor o horizonte valorativo do sujeito, ou conduzir processos de valoração que provoquem a assimilação de novos valores.

(...) [Entendemos que] os exercícios de clarificação são interessantes na medida em que favorecem a coerência da conduta com os próprios pensamentos, sentimentos e valores.

(...) As dinâmicas e os exercícios expressivos no campo da educação moral designam um conjunto de atividades que servem para que o aluno descubra e manifeste algum sentimento, experiência, pensamento ou valor. (...) Os exercícios expressivos mais comuns são os escritos de todo tipo,(...) os desenhos, as representações, os exercícios de mímica e os trabalhos audiovisuais. (PUIG, 1998, p.35-43)

Mas a professora ainda não estava satisfeita. Suas "sugestões sutis" pareceram não ter esclarecido aos alunos o bastante. Era preciso ser mais enfática, dividir com a classe toda o fato ocorrido e refletir com eles sobre o que haviam revelado em seus trabalhos, analisando a tendência que todos nós manifestamos e as possibilidades de mudanças. No entanto... qual seria a melhor forma de fazê-lo? E o tempo necessário para lidar com isso: quantas aulas mais ela poderia utilizar para essa atividade, diante do restante do programa, que propunha outros temas? Estes não seriam igualmente importantes?

Essa experiência, confirmando o que a professora já havia observado em 
outras situações, mostrava, mais uma vez, que as atividades que envolvem conteúdos de diferentes naturezas e uma participação maior dos alunos, necessitam de um tempo razoável para a sua realização. Mas são indispensáveis, conforme indicações já expressas em diferentes documentos que se referem à educação, tais como os Parâmetros Curriculares Nacionais:

O projeto educacional expresso nos Parâmetros Curriculares Nacionais demanda uma reflexão sobre a seleção de conteúdos, como também exige uma ressignificação, em que a noção de conteúdo escolar se amplia, para além de fatos e conceitos, passando a incluir procedimentos, valores, normas e atitudes. Ao tomar como objeto de aprendizagem escolar conteúdos de diferentes naturezas, reafirma-se a responsabilidade da escola com a formação ampla do aluno e a necessidade de intervenções conscientes e planejadas nessa direção." (BRASIL, 1997, p.73)

O texto relativo ao tema que estava sendo trabalhado em classe ocupava apenas o espaço de uma folha de sulfite, mas estava desencadeando um série de exercícios e discussões importantes que necessitavam de um bom tempo para serem desenvolvidos. E a professora sabia que o trabalho com a educação ambiental deveria ser assim mesmo: não se restringir à compreensão de fatos e conceitos. Sem menosprezá-los ou abandoná-los, era preciso ir além...

A Educação Ambiental é um elemento integrador (...) Para tanto, deverá servir não só para transmitir conhecimentos, mas também para desenvolver habilidades e atitudes que permitam ao homem atuar efetivamente no processo de manutenção do equilibrio ambiental (...) (KRASILCHIK, 1986, p.19591960)

Entretanto, sentia que em sua formação inicial fora preparada basicamente para o ensino do conteúdo conceitual, de modo que trabalhar com valores significava um desafio a mais. Como abarcá-lo convenientemente?

Todas essas idéias passavam-lhe pela cabeça. E as decisões tinham que ser rápidas, pois implicavam em ajustes para as aulas seguintes...

Optando por explorar melhor o que havia emergido entre os alunos, ela ampliou o momento da apreciação geral dos cartazes pela classe, acrescentando uma análise mais detalhada das produções. A tendência ocorrida foi então apresentada com destaque aos alunos, na tentativa de que estes também percebessem com clareza o valor revelado por seus desenhos e refletissem sobre o seu significado. A professora aproveitou a oportunidade para relembrá-los das questões referentes ao distanciamento progressivo de nossa sociedade com relação à natureza e a dicotomia marcante que se estabelece a partir daí, aspecto que havia sido comentado meses antes e que naquele momento 
reaparecia na produção deles mesmos.

Finalmente o estudo do tema com a classe foi encerrado, mas a professora permaneceu fazendo a si mesma várias indagações sobre sua atuação: não poderia ter agido de modo diferente? A exploração final não teria sido demasiado expositiva, ainda muito centrada em sua figura? Não poderia ter sido menos impositiva com os alunos?

Suas dúvidas se ampliaram mais ainda ao pensar em como avaliar a aprendizagem do conteúdo atitudinal: pelos cartazes elaborados, sabia que fora possível detectar alguma aprendizagem geral dos alunos quanto à compreensão dos conceitos envolvidos, através das figuras e frases elaboradas por eles, como também no momento da apreciação final dos cartazes pela classe. Mas, e quanto aos valores? Como avaliar essa aprendizagem? Seria possível essa avaliação? Teriam os alunos abalado a crença na separação sociedade-natureza, revelada pelos desenhos que fizeram? Seria possível alguma mudança em tão pouco tempo?

(...) É preciso atentar para o fato de que a avaliação de valores, atitudes $e$ procedimentos (...) é bastante dificil. (...) Ao colocar a possibilidade da avaliação de atitudes não se pode deixar de salientar os limites da atuação da escola nessa formação. Vale lembrar que a educação não pode controlar todos os fatores que interagem na formação do aluno e que não se trata de impor determinados valores, mas de ser coerente com os valores assumidos, de possibilitar aos alunos uma discussão sobre eles e a construção de critérios para a escolha pessoal.(BRASIL, 1998, p.39)

De uma coisa, porém, a professora estava certa: a atividade mostrou-lhe o quanto um professor precisa estar atento para lidar com a dimensão valorativa na educação, necessidade apontada por muitos daqueles que lidam com o assunto:

Os PCNs para o ensino fundamental, acompanhando as tendências atuais, trouxeram explicitamente para o ensino nacional a importância e a necessidade de se levarem em conta, no processo educativo, os aspectos valorativos. Os programas com a temática ambiental também ressaltam a importância de se considerarem os valores éticos e estéticos(...) Em experiências dessa natureza é necessário que o professor esteja preparado, tanto para evitar equívocos que comprometam os objetivos que pretenda alcançar, como para que não se percam oportunidades de exploração de tais aspectos, por não percebê-los emergindo do grupo de alunos. (BONOTTO, 1999, p.210,212)

\section{REFLEXÕES FINAIS}

Os valores estão presentes em qualquer atividade, quer se dê conta disso ou 
não. É preciso aprimorar nossa percepção para captá-los. E se o trabalho educativo com valores pode e deve receber um tratamento específico em aulas especificamente elaboradas para esse fim, deve ser também desenvolvido no dia-a-dia e a partir de sua manifestação ou captação espontânea e imprevista. Para exercer com maior segurança seu papel diante de todas essas situações, o professor precisa se preparar adequadamente, não somente com relação à fundamentação sobre esse trabalho, mas também com relação aos aspectos metodológicos que o envolvem.

Isso é prioritário ao se pensar na educação ambiental, pois, afinal,

(...) o ensino do meio ambiente não significa apenas transmitir conceitos ecológicos, é necessário também tratar o aspecto emocional do desenvolvimento dos estudantes, ajudando-os a esclarecerem e a expressarem suas impressões e valores quanto ao meio ambiente. Esta base emotiva é de suma importância pois é dela que nasce a dedicação e o compromisso perduráveis, que complementam os conhecimentos, na busca pelo indivíduo de uma melhor qualidade de vida. O elemento afetivo é um componente vital na Educação Ambiental. (CEROVSKY, 1977, p.58)

A importância do conteúdo atitudinal é reconhecida pelos educadores que lidam com a educação ambiental. Com freqüência encontram-se referências sobre a necessidade de se trabalhar com os valores éticos e estéticos relativos à essa temática. No entanto, muitos sentem-se inseguros para atuar nessa direção, menos comum no ensino, e diversas pesquisas na área têm apontado para a escassez de experiências significativas relacionadas à integração desse conteúdo de ensino aos demais.

Por essa razão acreditamos no valor e necessidade da divulgação e análise de pesquisas e experiências referentes a essa integração, estimulando a sua multiplicação e ensaiando um passo importante em direção à sua efetivação.

\section{REFERÊNCIAS BIBLIOGRÁFICAS}

BONOTTO, D.M.B. A temática ambiental e a escola pública de ensino médio: conhecendo e apreciando a natureza. Rio Claro, 278 p. Dissertação (Mestrado em Conservação e Manejo de Recursos) - Centro de Estudos Ambientais, UNESP, 1999. p.210,212.

BRASIL. Ministério da Educação e do Desporto, Secretaria de Educação Fundamental. Parâmetros Curriculares Nacionais, $1^{\circ}$ a $4^{\circ}$ séries, Introdução. 1997, p.73.

BRASIL. Ministério da Educação e do Desporto, Secretaria de Educação Fundamental. Parâmetros Curriculares Nacionais, $5^{\circ}$ a $8^{\circ}$ séries, Temas transversais. 1998, p.39. 
CARVALHO, L.M. A temática ambiental e a escola de $1^{\circ}$ grau. São Paulo, 282 p. Tese (Doutorado em Educação) - Faculdade de Educação, USP, 1989. p.219-220.

CEROVSKY, J. Recursos didáticos para la educación ambiental. In: Tendencias de la educación ambiental, UNESCO, 1977. p.58.

GRÜN, M. Ética e Educação Ambiental: a conexão necessária. Campinas: Papirus Editora, 1996. 120 p.

KRASILCHIK, M. Educação Ambiental na escola brasileira - passado, presente e futuro. Ciência e Cultura. São Paulo. v.38, n.12, p.1959-1960,1986.

MIZUKAMI, M.G.N. Casos de ensino e aprendizagem profissional da docência. In: ABRAMOWICZ, A. e MELLO, R.R. de (Org.) Educação: pesquisas e práticas. Campinas: Papirus Editora, 2000. 176 p.

PUIG, J.M. Ética e valores: métodos para um ensino transversal. São Paulo: Casa do Psicólogo, 1998, 226 p. (Coleção Psicologia e Educação). 